\title{
Discussion on Coupling Effect in Structural Load of FOWT for Condensing Wind and Wave Bins for Spectral Fatigue Analysis
}

\author{
Tomoya Inoue ${ }^{1}$, Ahmad Adilah ${ }^{1}$, Kazuhiro Iijima ${ }^{1, *}$, Sho Oh ${ }^{2}$ and Hideyuki Suzuki ${ }^{3}$ \\ 1 Department of Naval Architecture and Ocean Engineering, Osaka University, Osaka 565-0871, Japan; \\ Tomoya_Inoue@naoe.eng.osaka-u.ac.jp (T.I.); Ahmad_Adilah@naoe.eng.osaka-u.ac.jp (A.A.) \\ 2 Renewable Energy Department, Nippon Kaiji Kyokai, Tokyo 102-8567, Japan; s-oh@classnk.or.jp \\ 3 Department of Systems Innovation, The University of Tokyo, Tokyo 113-8654, Japan; \\ suzukih@sys.t.u-tokyo.ac.jp \\ * Correspondence: iijima@naoe.eng.osaka-u.ac.jp; Tel.: +81-6-6879-7585
}

Received: 13 November 2020; Accepted: 16 November 2020; Published: 18 November 2020

\begin{abstract}
Floating Offshore Wind Turbines (FOWTs) are subject to combined wind and wave loads. The response is not given as a simple sum of the wind-only response and wave-only response due to nonlinear coupling effects, which makes the structural analysis more complex and time-consuming. When a spectral approach for the structural fatigue analysis is considered, it is necessary to accurately estimate the variance of the combined stress taking account of the coupling effect. In this study, firstly the characteristics of the combined response are investigated. It is found out the coupling effects are two-fold; one is the aerodynamic exciting load increase for the forced motion in the wave frequency range. The other is the aerodynamic damping effect due to the increase of the relative wind speed, which is prominent in the structural vibration frequency range. Mathematical models to account for these coupling effects are developed. Then, a series of simulations are performed on three types of FOWTs to validate the models. It is shown that the characteristics of the combined response are different among the three types of the platforms and the developed model can explain the increase/decrease of the variance of the combined stress when compared with two decoupled wave-only and wind-only simulations.
\end{abstract}

Keywords: FOWT; coupling effect; fatigue; spar; semi-submersible; TLP; numerical simulation; spectral approach; response characteristics

\section{Introduction}

Under the recent anxiety of energy shortage and environmental pollution, renewable energy resources are gaining its popularity. Some renewable energy resources, such as wind, tidal, geothermal and solar, are expected to replace fossil fuels. Offshore wind energy is likely to develop more because of its electric power potential and stable supply. The wind at sea is less turbulent and the wind speed is higher than on land. Offshore wind turbines may be expected to have higher output. Concerns about disturbing human dwellings are less offshore because they are located distant from the habitation areas. With these advantages, the development of offshore wind farm is heading towards the deeper waters. Therefore, Floating Offshore Wind Turbines (FOWTs) are becoming popular. Since FOWTs are subjected to various types of uncertain loads, such as wind, wave, current and mooring force, the coupled dynamics need to be considered to analyze the whole FOWT structure as a system. Then, numerical simulation tools for the FOWT system have also been developed. One of the most popular tools is FAST [1]. Many studies were conducted with FAST. NK-UTWind [2] has been developed as a numerical simulation tool for a coupled time-domain simulation. NK-UTWind uses 
FAST for the evaluation of aerodynamic loads on the rotor nacelle assembly (RNA) while it separately formulates the substructure below the RNA as a 3D frame structure subjected to wave loads by using finite element method (FEM). The coupling between the aerodynamic and hydrodynamic response are fully considered. One of the advantages of this method is that the structural member forces are directly evaluated by the simulation without performing the subsequent structural analysis.

Since FOWTs are expected to operate for 20-25 years, the fatigue strength is one of the key factors in securing the safety. In order to estimate the fatigue damage, several methods have been adopted. One of the most widely used methods is the Palmgren-Miner's rule for the stress range histogram obtained by the Rain-flow counting method, which was proposed by Matsuishi and Endo, et al. [3]. This method may be used for general stress histories including non-Gaussian and wide-banded processes. From the direct time series data of stress cycles, stress histograms are obtained and the cumulative fatigue damage is estimated according to the S-N curve and the Palmgren-Miner's rule. Li, et al. [4] used the Rain-Flow counting method for the OC3-Hywind spar-type platform. While the Rain-flow counting method can estimate the fatigue damage directly and its practicality has been widely accepted, it requires immense computational complexity since one needs to consider numerous sets of combinations of wind and wave conditions for estimating the cumulative fatigue damage of FOWTs during the design life of 20-25 years.

Then, the other approach that takes less time for the simulations has been pursued. If the stress cycles on structures are assumed to be Gaussian and narrow-banded, the probability density function (PDF) of the stress peaks may be assumed to follow Rayleigh distribution and the fatigue strength can be estimated mathematically [5]. Linear transfer functions may be used to evaluate the variance of stress. It is known as frequency domain-based approach, which has good advantages in terms of computational time. Abhishek [6] presented a frequency domain approach for the fatigue damage calculation of a bottom-fixed structure for offshore wind turbine. Compared to the direct time domain-based calculation, the fatigue damage can be assessed very quickly without the loss of accuracy. Kvittem and Moan [7] proposed several frequency domain fatigue analyses for a semi-submersible platform. In the research, it is shown that the method gives good results under some of the environmental conditions. Although there are some limitations in frequency domain methods, accurate results are obtained in shorter time. Van der Tempel [8] developed a frequency-domain method for a fixed monopile offshore wind turbine. By comparing to a time-domain method, the frequency-domain method shows acceptable accuracy for fixed offshore wind turbines. In this research, the wind turbine is modelled on a rigid support structure while the support structure can be modelled in any FEM program. In this method, the response spectra due to wind and due to wave are calculated separately and then added linearly. Unlike fixed offshore wind turbine, one needs to consider the interaction between wind and wave load on FOWTs.

The frequency domain-based approach can be extended to account for non-Gaussian and wide-banded processes. A spectral approach based on time-domain simulations has also been developed. The peaks of non-Gaussian and wide-banded process may be fitted to probability distributions other than Rayleigh distribution. Huang and Moan [9] derived a formula for the fatigue damage due to combined high and low frequency stress. By using Winterstein's transformation [10], the method is extended to the combination of non-Gaussian loads. Gao and Moan [11] estimated the fatigue damage of mooring chain under combined low frequency and wave frequency loads which are both non-Gaussian processes. The Dirlik method [12], which is the combination of one exponential distribution and two different Rayleigh distributions, is expected to be an effective method for the fatigue strength. Patrick, et al. [13] introduce the Dirlik method to estimate the fatigue damage for onshore wind turbines. It gives a good result on tower base bending moment but not on blade bending moment. Adilah, et al. [14] also suggested the Dirlik method for the estimation of the peak stress of the semi-submersible platform. While it gives a good approximation, he pointed out there are some differences between the simple sum of wave-only case and wind-only case and combined case due to the coupling effect. The validity of the spectral approaches has been confirmed for various 
applications, however, further improvements are necessary to achieve more accurate estimation of the fatigue damage; the variance of the stress need to be estimated taking account of the coupling effect between wind load and wave load.

In this study, mathematical models to evaluate the nonlinear coupling effect are proposed based on investigations into the characteristics of the combined response, with an aim of reducing the total combinations of bins of wind and waves for fatigue damage. It is discussed that the coupling effects are two-fold; one is the aerodynamic exciting load increase for the forced motion in the wave frequency range. The other is the aerodynamic damping effect due to the increase of the relative wind speed, which is prominent in the structural vibration frequency range. Mathematical models to evaluate the coupling effects is developed based on the discussion. Then, a series of simulations are performed on three types of FOWTs including spar, semisubmersible and tension leg platform (TLP) to confirm the validity of the models. It is shown that the characteristics of the combined response are different among the three types of the platforms and the developed model can explain the increase/decrease of the variance of the combined stress due to the coupling when compared with two decoupled wind-only and wave-only simulations.

\section{Theoretical Backgrounds}

In this section, simulation methods are briefly reviewed. It is explained that the nonlinear coupling effects arise mainly from the aerodynamic loads which is a function of the relative velocity. Mathematical models to account for the coupling effects are developed. In the model development, it is assumed that the blade pitch angle is fixed. This assumption may apply to the conditions where the blade pitch control is not actively controlled; wind speed below the rated speed around $12 \mathrm{~m} / \mathrm{s}$.

\subsection{Equation of Motion}

In the present study, NK-UTWind is used for the time-domain simulation of FOWTs under combined wind and wave loads. In this method, the whole structure is divided into the rotor part and the structure part (tower, substructure and mooring). The rotor part consists of nacelle and blade. The aerodynamic force is evaluated by using FAST code in which the blade element momentum theory is adopted [15]. It is calculated by the combination of the blade element theory and the momentum theory. The blade element theory assumes that a blade is divided into some elements and the aerodynamic forces can be calculated. On the other hand, the momentum theory assumes that the loss of pressure or momentum in the rotor plane is caused by the work done by the airflow passing through the rotor plane on the blade elements. When these equations are solved iteratively, the axial force on blade and torque considering the induced velocities are evaluated. The thrust force is expressed as given in Equation (1).

$$
F^{\text {aero }}=\frac{1}{2} \rho_{\text {air }} S C_{T} W_{\text {rotor }}\left|W_{\text {rotor }}\right|,
$$

where $\rho_{\text {air }}$ is the air density, $S$ the rotor swept area, $C_{T}$ the thrust force coefficient and $W_{\text {rotor }}$ the wind velocity at the rotor.

The aerodynamic and inertia loads on the rotor part are integrated into the structure part. The structure is formulated with finite element model and discretized into node elements and beam elements. Each node has three translational and three angular degrees of freedom. Thus, it can be formulated schematically as given in Equation (2).

$$
[\mathbf{M}]\{\ddot{x}\}+[\mathbf{C}]\{\dot{x}\}+[\mathbf{K}]\{x\}=\left\{F^{\text {hydro }}+\boldsymbol{F}^{\text {lines }}+\boldsymbol{F}^{\text {buoyancy }}+\boldsymbol{F}^{\text {aero }}\right\},
$$

where $[\mathbf{M}]$ is the mass matrix whose dimension is $6 \mathrm{~N}$ for the structural model of $N$ nodes, $[\mathbf{C}]$ the damping matrix and $[\mathbf{K}]$ the structural stiffness matrix. $x$ denotes the nodal displacement vector and its first derivative and second derivative denote the velocity and acceleration vectors, respectively. 
The right-hand side vector is composed of four force components, that is, the hydrodynamic force, the forces from mooring lines, the restoring force and the aerodynamic force. The hydrodynamic force is evaluated based on Morison's equation [16], as given in Equation (3). It can be applied for slender structures which are hydrodynamically transparent.

$$
F^{\text {hydro }}=\rho \frac{\pi D^{2}}{4} \dot{v}+C_{m} \rho \frac{\pi D^{2}}{4}(\dot{v}-\ddot{x})+C_{d} \frac{1}{2} \rho D(v-\dot{x})|v-\dot{x}|,
$$

where $\rho$ is the fluid density, $D$ the diameter of column element and $v$ the fluid particle velocity. And $C_{m}$ and $C_{d}$ denote the added mass coefficient and drag force coefficient, respectively. The mooring force can be evaluated by either quasi-static catenary calculation, lumped-mass method or linear spring.

The calculation of NK-UTWind proceeds with time marching steps. At each time step, the thrust force from the rotor is calculated with FAST and it is passed to NK-UTWind at the tower top, as the boundary conditions. Then, the structural response is evaluated with NK-UTWind. From NK-UTWind, the displacement and velocity at the tower top are fed back to FAST as the boundary conditions. The time series of the whole system are evaluated with weakly coupled analysis.

\subsection{Mechanism of the Coupling Effect}

The structural analysis of FOWT is more complex than that of bottom-fixed wind turbine in a point that the floating platform has more degrees of freedom than the fixed one. that is, the rigid body motion of the platform needs to be considered in the evaluation of the structural analysis. Both the hydrodynamic (drag force term) and aerodynamic forces depend on the relative velocity between wind speed (or water particle velocity) and the platform velocity. Meanwhile, the rigid body motions of the platform are mostly induced by the waves [14]. Then, the coupling term comes mostly from the aerodynamic force. When the tower structure modelled as a beam with a nacelle mass supported by a floating platform (See Figure 1), the aerodynamic force and the structural response of the tower or the substructure may schematically be modelled as in Equation (4).

$$
\begin{gathered}
m\left(\ddot{x}+\ddot{x}_{\text {tower }}+\ddot{l}\right)+c \dot{x}_{\text {tower }}+k x_{\text {tower }} \\
=\frac{1}{2} \rho_{\text {air }} S C_{T}\left|W-\left(\dot{x}+\dot{x}_{\text {tower }}+l \dot{\theta}\right)\right|\left\{W-\left(\dot{x}+\dot{x}_{\text {tower }}+l \dot{\theta}\right)\right\},
\end{gathered}
$$

where $m$ is the mass of the RNA, $l$ the distance to the centroid of the nacelle from the center of gravity of the total system, $k$ the structural stiffness of the tower, $c$ the system damping. $C_{T}$ is the thrust force coefficient, $S$ the rotor swept area, $\rho_{\text {air }}$ the air density, $W$ the instantaneous wind velocity. $x$ is the forced platform displacement, $\theta$ the forced platform angular displacement (i.e., pitch), $x_{\text {tower }}$ the displacement due to the tower deflection. Wind velocity is divided into the steady component $\bar{w}$ and stochastic component $w^{\prime}$.

By assuming that the steady wind component is larger than the other velocity terms such as $w^{\prime}, \dot{x}$, $\dot{x}_{\text {tower }}, \dot{l} \dot{\theta}$ and by omitting the higher order terms, Equation (4) can read as given in Equation (5).

$$
\begin{gathered}
m \ddot{x}_{\text {tower }}+\left(c+\rho_{\text {air }} S C_{T} \bar{w}\right) \dot{x}_{\text {tower }}+k x_{\text {tower }} \\
=\frac{1}{2} \rho_{\text {air }} S C_{T} \bar{w}^{2}+\rho_{\text {air }} S C_{T} \bar{w} w^{\prime}-m(l \ddot{x}+l \ddot{\theta})-\rho_{\text {air }} S C_{T} \bar{w}(\dot{x}+l \dot{\theta}) .
\end{gathered}
$$

In what follows, the coupling effects are categorized into two. One is for the low frequency range and the other for the vibration (resonance) frequency range. The forced motion of the floating structure is relevant in the low frequency range. 


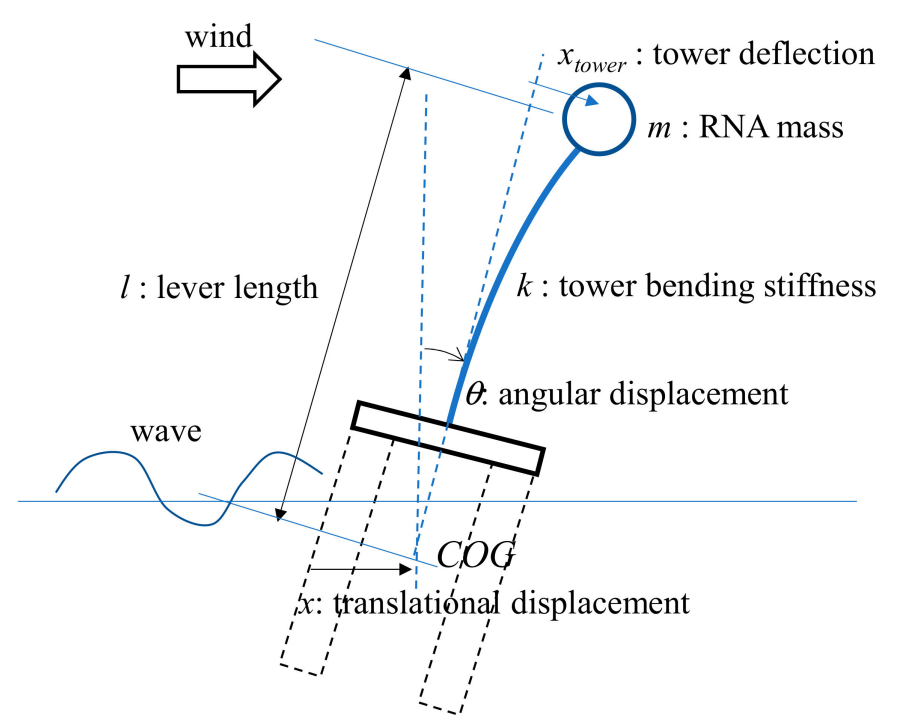

Figure 1. Tower structural model supported by a floating platform.

\subsubsection{Coupling Effect in Low Frequency Range}

In the low frequency range where the inertia force is smaller than the restoring force, the inertia terms may be dropped. Focusing on the right-hand side of Equation (5), the coupling term appears only in the last term while the first and second term depend on only wind and the third term represents the inertia force due to the platform acceleration induced by the waves. The last term in Equation (5) gives the coupled force with the wave frequency. It has the dominant energy coinciding with the wave energy spectrum range.

For simplicity, if one considers the case when the structure is subjected to the forced pitch motion due to the wave loads given by as $\theta=\theta_{0} \cos \omega t$, Equation (5) may be expressed as given in Equation (6), dropping the steady component.

$$
\begin{gathered}
m \ddot{x}_{\text {tower }}+\left(c+\rho_{\text {air }} S C_{T} \bar{w}\right) \dot{x}_{\text {tower }}+k x_{\text {tower }} \\
=\rho_{\text {air }} S C_{T} \bar{w} w^{\prime}+m l \omega^{2} \theta_{0} \cos \omega t+\rho_{\text {air }} S C_{T} \bar{w} l \omega \theta_{0} \sin \omega t,
\end{gathered}
$$

where $\theta_{0}$ is the amplitude of the pitch motion, which is proportional to wave height. When the acceleration and velocity terms are dropped. the tower deflection is given as in Equation (7).

$$
x_{\text {tower }}=\frac{\rho_{\text {air }} S C_{T} \bar{w} w^{\prime}}{k}+\frac{m l \omega^{2} \theta_{0} \cos \omega t}{k}+\frac{\rho_{a i r} S C_{T} \bar{w} l \omega \theta_{0} \sin \omega t}{k} .
$$

The last term is regarded as the coupling term. Since the velocity and acceleration are regarded uncorrelated, they can be simply summed when discussing the variance. It is natural to assume that wind and waves are uncorrelated. Therefore, in the low frequency range, the total loads are decomposed into three components and the variance of the response to the total loads may be given as in Equation (8).

$$
\sigma_{\text {low }}^{2}=\sigma_{\text {wind }}^{2}+\sigma_{\text {wave }}^{2}+\sigma_{\text {couple }}^{2} .
$$

It indicates that the spectrum of the structural load in the wave frequency range increases due to the coupling effect. 


\subsubsection{Coupling Effect in Vibration Frequency Range}

On the other hand, the inertia term and restoring force term are balanced around the vibration frequency range in the left-hand side of Equation (6). In the right-hand side, the inertia force term dominates. Then, from Equation (6), the response can be approximated as follows.

$$
x_{\text {tower }}=\frac{m l \omega^{2} \theta_{0} \cos \omega t}{\left(c+\rho_{\text {air }} S C_{T} \bar{w}\right) \omega} \approx \frac{m l \omega^{2} \theta_{0} \cos \omega t}{c \omega}-\frac{\rho_{\text {air }} S C_{T} \bar{w}}{c} \frac{m l \omega^{2} \theta_{0} \cos \omega t}{c \omega} .
$$

The second term acts as the coupling term. The first term and the second term are always correlated and the coupling term reduces the motion response because it acts as the additional aerodynamic damping.

In the high frequency range, the variance of the response to the total loads is given as in Equation (10).

$$
\sigma_{\text {high }}^{2}=(1-\alpha)^{2} \sigma_{\text {wave }}^{2} \approx(1-2 \alpha) \sigma_{\text {wave }}^{2}
$$

where $\alpha=\frac{\rho_{a i r} S C_{T} \bar{w}}{c}$ is the aerodynamic damping ratio. It indicates that the spectrum of the structural load decreases in the vibration frequency range due to the coupling effect. If the vibrations are excited by the aerodynamic loads, a similar discussion may apply. That is, $\sigma_{\text {high }}^{2} \approx(1-2 \alpha) \sigma_{\text {wind }}^{2}$ in this case.

\section{Simulation Model}

\subsection{FOWT Models}

Three types of FOWTs (spar, semi-submersible and TLP) are considered in this research. Main dimensions of all FOWTs are summarized in Table 1 and the overviews of the platform designs are shown in Figure 2. A brief explanation of each platform is made in the following part. The concepts of designing FOWTs are further described by the papers [17-19]. In the literatures, the experiments were carried out with those scaled models for the sake of understanding their motion characteristics. This time, simulation models of the same platforms are created and a series of simulations is performed using NK-UTWind (See, Section 2.1).

The wind turbine mounted on top of the tower is modeled according to the NREL 5-MW baseline wind turbine [20], which is the three-bladed upwind turbine. Each blade has $61.5 \mathrm{~m}$ long. Other gross properties of the wind turbine are listed in Table 2. On modeling, each blade is discretized into 49 nodes and connected with 2-node elements. The structure part, including the floating platform, nacelle and tower, are modeled as beam elements. In this study, the same tower, nacelle and wind turbine are assumed to be installed on each floating structures for the purpose of comparison. The table summarizes the natural frequencies. The main dimensions of the tower are listed in Table 3 . The tower is discretized into 4 beam elements which has $20 \mathrm{~m}$ each. The bottom of the tower is rigidly fixed to the floating platforms.

The hydrodynamic coefficient for Morison's equation is taken to be 1.0 for cylinder column, 1.5 for rectangular beam, respectively. Rayleigh damping model is adopted and the coefficient for each matrix of equations of motion is set at 0.05 . Mooring line is modeled as a linear spring. Initial tension is determined by subtracting the platform mass and ballast from the displacement. Properties of mooring for each platform are listed in Table 4. 
Table 1. Main dimensions of three Floating Offshore Wind Turbines (FOWTs).

\begin{tabular}{cccc}
\hline & Spar & Semi-Submersible & TLP \\
\hline Displacement & $9408 \mathrm{tons}$ & $13126 \mathrm{tons}$ & $3100 \mathrm{tons}$ \\
Draft & $109.3 \mathrm{~m}$ & $25.0 \mathrm{~m}$ & $21.0 \mathrm{~m}$ \\
KG & $90.0 \mathrm{~m}$ & $113.9 \mathrm{~m}$ & $87.1 \mathrm{~m}$ \\
Tower height from the still water line & $51.0 \mathrm{~m}$ & $15.0 \mathrm{~m}$ & $26.0 \mathrm{~m}$ \\
Cross-sectional area of rectangular beam & - & $6.0 \mathrm{~m} \times 6.0 \mathrm{~m}$ & $5.2 \mathrm{~m} \times 2.6 \mathrm{~m}$ \\
Surge natural frequency & $0.0369 \mathrm{rad} / \mathrm{s}$ & $0.0392 \mathrm{rad} / \mathrm{s}$ & $0.128 \mathrm{rad} / \mathrm{s}$ \\
Sway natural frequency & $0.0369 \mathrm{rad} / \mathrm{s}$ & $0.0392 \mathrm{rad} / \mathrm{s}$ & $0.131 \mathrm{rad} / \mathrm{s}$ \\
Heave natural frequency & $0.165 \mathrm{rad} / \mathrm{s}$ & $0.341 \mathrm{rad} / \mathrm{s}$ & $1.90 \mathrm{rad} / \mathrm{s}$ \\
Roll natural frequency & $0.294 \mathrm{rad} / \mathrm{s}$ & $0.269 \mathrm{rad} / \mathrm{s}$ & $1.75 \mathrm{rad} / \mathrm{s}$ \\
Pitch natural frequency & $0.280 \mathrm{rad} / \mathrm{s}$ & $0.256 \mathrm{rad} / \mathrm{s}$ & $1.75 \mathrm{rad} / \mathrm{s}$ \\
Yaw natural frequency & $0.287 \mathrm{rad} / \mathrm{s}$ & $0.242 \mathrm{rad} / \mathrm{s}$ & $0.226 \mathrm{rad} / \mathrm{s}$ \\
Eigen frequency of the first flexible & $3.27 \mathrm{rad} / \mathrm{s}$ & $2.10 \mathrm{rad} / \mathrm{s}$ & $3.41 \mathrm{rad} / \mathrm{s}$ \\
deformation (tower 1st bending) & & & \\
\hline
\end{tabular}

Table 2. Gross properties of the NREL 5-MW baseline wind turbine.

\begin{tabular}{cc}
\hline Rating & $5 \mathrm{MW}$ \\
Rotor orientation, configuration & Upwind, 3 blades \\
Rotor, hub diameter & $126 \mathrm{~m}, 3.0 \mathrm{~m}$ \\
Cut-in, Rated, Cut-out wind speed & $3.0 \mathrm{~m} / \mathrm{s}, 11.4 \mathrm{~m} / \mathrm{s}, 25.0 \mathrm{~m} / \mathrm{s}$ \\
Cut-in, Rated rotor speed & $6.9 \mathrm{rpm}, 12.1 \mathrm{rpm}$ \\
Rotor mass & 110 tons \\
\hline
\end{tabular}

Table 3. Main dimensions of the tower.

\begin{tabular}{cc}
\hline Length & $80.0 \mathrm{~m}$ \\
Tower mass & $130 \mathrm{tons}$ \\
Diameter & $5.0 \mathrm{~m}$ \\
Thickness & $0.040 \mathrm{~m}$ \\
\hline
\end{tabular}

Table 4. Properties of the mooring.

\begin{tabular}{cccc}
\hline & Spar & Semi-Submersible & TLP \\
\hline The number of mooring lines & 4 & 3 & 3 \\
Horizontal distance & $566 \mathrm{~m}$ & $485 \mathrm{~m}$ & $0 \mathrm{~m}$ \\
Vertical distance & $249 \mathrm{~m}$ & $275 \mathrm{~m}$ & $279 \mathrm{~m}$ \\
Initial tension & $2.20 \times 10^{3} \mathrm{kN} / \mathrm{m}$ & $2.43 \times 10^{2} \mathrm{kN} / \mathrm{m}$ & $5.00 \times 10^{3} \mathrm{kN} / \mathrm{m}$ \\
Spring constant & $1.00 \times 10^{1} \mathrm{kN} / \mathrm{m}$ & $5.00 \times 10^{1} \mathrm{kN} / \mathrm{m}$ & $1.00 \times 10^{4} \mathrm{kN} / \mathrm{m}$ \\
\hline
\end{tabular}

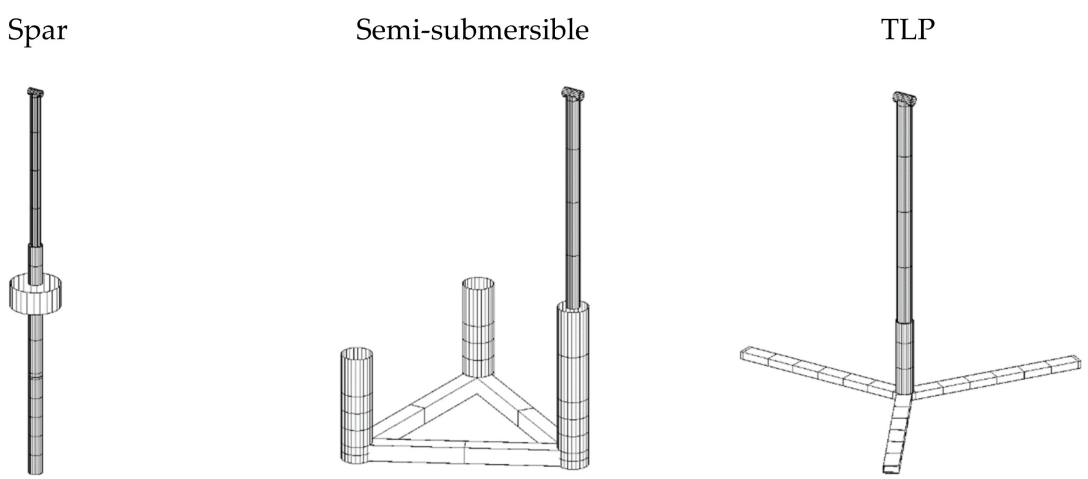

Figure 2. The overview of the platform designs. 


\subsubsection{Spar}

The spar platform is a single-column structure and the draft of the column in this study is about $110.0 \mathrm{~m}$ while the diameter is $7.0 \mathrm{~m}$. It has a large hull in the middle, which has the diameter of $25.0 \mathrm{~m}$ and the height of $11.0 \mathrm{~m}$ at the water depth $10.0 \mathrm{~m}$ below the still water line. This middle hull contributes to raising the center of buoyancy and the increase the stability while the hydrodynamic exciting force exerted on the middle hull may increase. Four fairleads are attached at $51.0 \mathrm{~m}$ above the keel and the platform is moored to seabed by catenary chain lines. The four mooring lines are oriented at 45, 135, 225 and 315 degrees against the wind direction from the weather side. The substructure platform model consists of 13 nodes and 12 beam elements, the column is subdivided into two beam elements for the part above the middle hull, one beam element for the middle hull and nine beam elements for the substructure below the middle hull.

\subsubsection{Semi-Submersible}

This semi-submersible platform has three columns connected at the bottom with the square lower hull of $6.0 \mathrm{~m}$ on one side. The lower hull is located at $19.0 \mathrm{~m}$ below the still water line. The columns are located at the top of a triangle, which are placed $75.0 \mathrm{~m}$ apart from each other. The tower is located on one of the columns. The column below the tower has the height of $53.0 \mathrm{~m}$. The other columns have a height of $33.0 \mathrm{~m}$. Regarding the mooring system, the original concept is a single point mooring allowing for weather-vaning. However, this concept is abandoned this time and a usual catenary type mooring system is adopted. Fairleads are attached to the bottom of columns. The platform model consists of 25 nodes and 25 elements. The column below the tower is discretized into 7 elements, the other column into 6 elements and each lower hull is divided in the center and modelled as 2 elements. From the eigenvalue analysis, a mode relating to the pitch bending is observed at $2.10 \mathrm{rad} / \mathrm{s}$. Figure 3 shows the eigen mode corresponding to the 1 st tower bending.

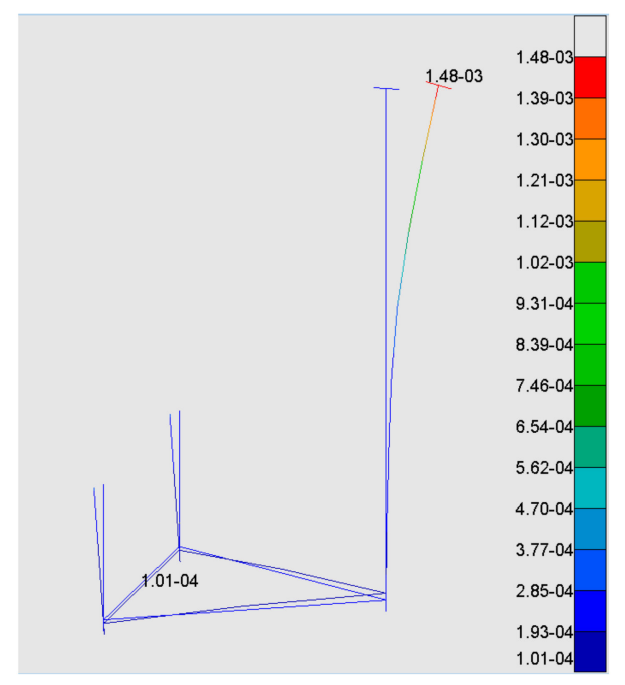

Figure 3. Eigen mode of the semi-submersible platform at $2.10 \mathrm{rad} / \mathrm{s}$.

\subsubsection{TLP}

The TLP platform in this study is composed of the center column and three rectangular lower hulls. The center column has the diameter of $6.0 \mathrm{~m}$ and the height of $28.0 \mathrm{~m}$. The lower hulls have the length of $64.0 \mathrm{~m}$ each and whose cross-sectional are $5.2 \mathrm{~m} \times 2.6 \mathrm{~m}$, connected at the bottom of the column. Thus, the lower hulls are located at $18.4 \mathrm{~m}$ below the still water line. The relatively long lower hull prevents the platform from capsizing due to slacking mooring lines. The detailed concept of how to calculate the slacking is explained in Reference [19]. Mooring lines are attached $1.0 \mathrm{~m}$ inside the end of lower hulls and lead straight down to seabed. The platform model consists of 30 nodes 
and 29 elements. The center column is discretized into 5 elements and each lower hull consists of 8 elements.

\subsection{Simulation Conditions}

Table 5 summarizes all the combinations of environmental conditions adopted in the study. For wind, both steady and stochastic wind (intensity 25\%) are considered. The stochastic wind is generated by Turbsim [21]. Its power spectrum is based on the Kaimal model [22]. Its turbulence intensity corresponds to the standard Normal Turbulence Model in IEC 61400-1 [22]. For waves, both regular and irregular wave can be considered. This time all the simulations are performed in irregular waves. The power spectrum of the irregular waves is based on ISSC model [23]. As the simulation case, wave-only condition (Case 1, 2, 3), wind-only condition (Case 4, 8, 12) and combined wind and wave condition are included. In every simulation, the wind and wave direction is aligned with the rotor axis.

Table 5. All the environmental conditions.

\begin{tabular}{cccccccc}
\hline & $\overline{\boldsymbol{w}}$ & $\boldsymbol{H}_{\boldsymbol{s}}(\mathbf{m})$ & $\boldsymbol{T}_{\boldsymbol{p}}(\mathbf{s})$ & & $\begin{array}{c}\overline{\boldsymbol{w}} \\
(\mathbf{m} / \mathbf{s})\end{array}$ & $\boldsymbol{H}_{\boldsymbol{s}}(\mathbf{m})$ & $\boldsymbol{T}_{\boldsymbol{p}}(\mathbf{s})$ \\
\hline Case 1 & 0.0 & 1.5 & 10.0 & Case 10 & 5.0 & 3.0 & 10.0 \\
Case 2 & 0.0 & 3.0 & 10.0 & Case 11 & 5.0 & 6.0 & 10.0 \\
Case 3 & 0.0 & 6.0 & 10.0 & Case 12 & 8.0 & 0.0 & - \\
Case 4 & 3.0 & 0.0 & - & Case 13 & 8.0 & 1.5 & 10.0 \\
Case 5 & 3.0 & 1.5 & 10.0 & Case 14 & 8.0 & 3.0 & 10.0 \\
Case 6 & 3.0 & 3.0 & 10.0 & Case 15 & 8.0 & 6.0 & 10.0 \\
Case 7 & 3.0 & 6.0 & 10.0 & Case 16 & 8.0 & 1.5 & 6.45 \\
Case 8 & 5.0 & 0.0 & - & Case 17 & 8.0 & 3.0 & 6.45 \\
Case 9 & 5.0 & 1.5 & 10.0 & Case 18 & 8.0 & 6.0 & 6.45 \\
\hline
\end{tabular}

To obtain the sufficient time series data, simulation time length in each case is set to $2 \mathrm{~h}$. $\Delta t=0.01 \mathrm{~s}$ is set for the time step of the simulation. Figure 4 shows the simulations at different time step. Except for $\Delta t=0.1 \mathrm{~s}$, there are almost similar time histories of surge motion. Therefore, $\Delta t=0.01 \mathrm{~s}$ seems to be sufficient for the simulation. The bending stress at the connection point between tower and substructure is evaluated for fatigue damage estimation. For Case 16, 17, 18, the simulations are made only for the semi-submersible platform.

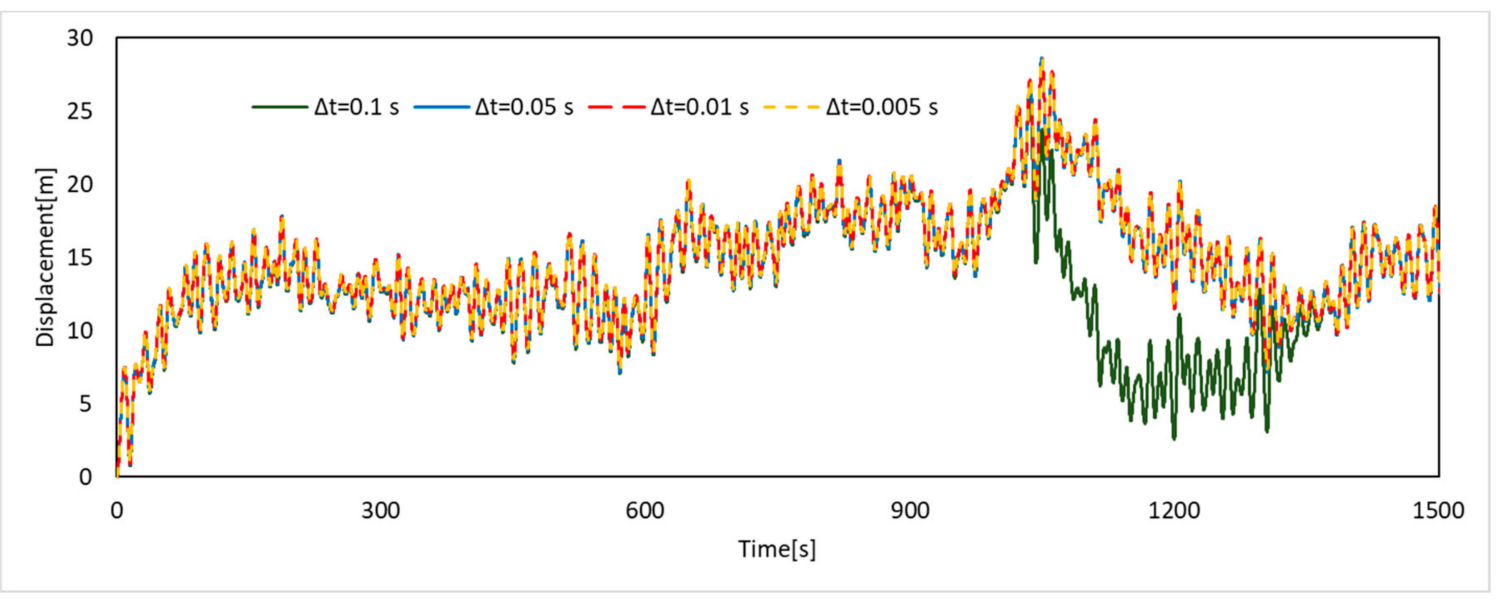

Figure 4. Time series with varying time step in surge direction. 


\section{Results and Discussions}

\subsection{Aerodynamic Load Characteristics}

Figure 5 shows the time series of wave elevation while Figure 6 shows the time series of the thrust force measured at tower top of the spar platform under the combined wind and wave loads and wind-only cases. From these diagrams, it is understood that the thrust force fluctuates with the wave elevation. It is explained as discussed in Section 2.2 that the relative wind speed at the tower top becomes different from the wind-only case due to the rigid body motions induced by the waves. The thrust force subsequently increases the variance of the bending stress in wave frequency range.

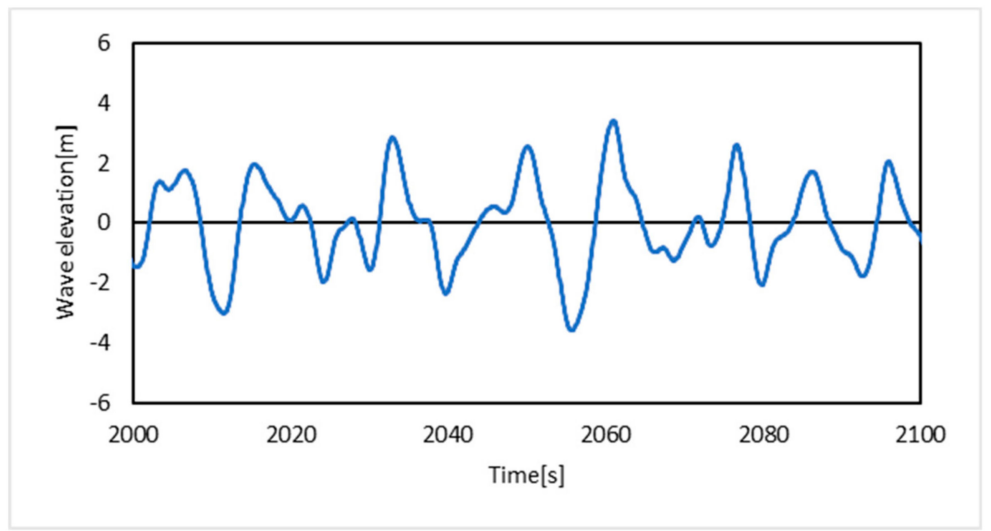

Figure 5. Time series of wave elevation (Case 3, 15).

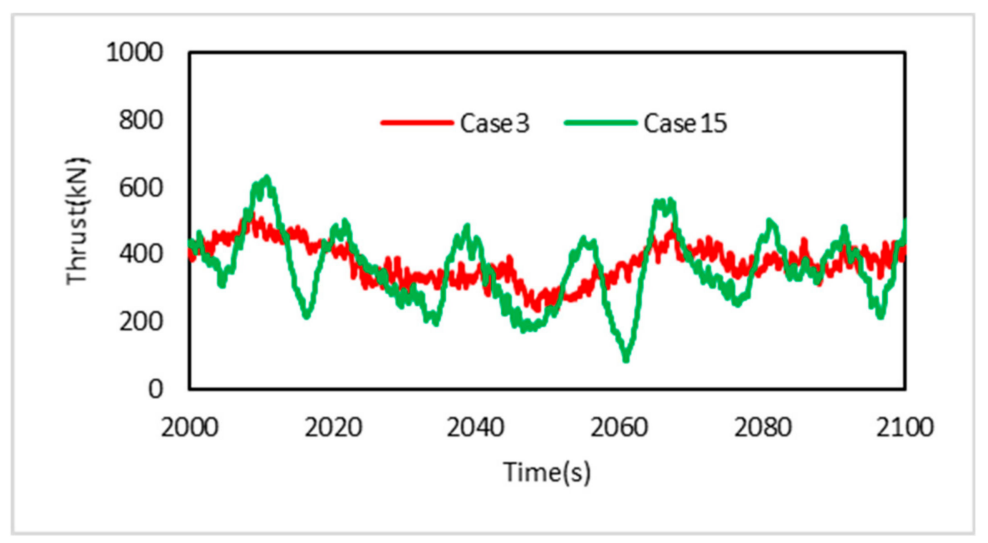

Figure 6. Time series of thrust force (Case 3, 15).

\subsection{Steady Wind and Irregular Wave Condition}

For all the FOWT platforms, 2-h simulations under wind-only, wave-only and combined conditions are conducted, respectively. The variances of bending stress are calculated from the respective time histories of two hours and the coupling effects in terms of the variance are evaluated by subtracting the sum of the variance of the wind-only and wave-only simulation cases $\sigma_{\text {wind }}^{2}+\sigma_{\text {wave }}^{2}$ from that of combined case $\sigma_{\text {com }}^{2}, \sigma_{\text {wind }}^{2}$ and $\sigma_{\text {wave }}^{2}$ respectively denote the variance of the wind-only and wave-only simulation cases while $\sigma_{\text {com }}^{2}$ does the variance of the combined wind and wave cases.

Figures 7-9 compare the time histories of the stress at tower base and its power spectral density curves (PSDs). In the case of the spar platform, the power spectrum in the wave frequency range is larger than the other two platform cases. This means that the spar platform undergoes the rigid body motions due to the wave load. Also, a small peak can be found around 3.0-4.0 rad/s even though it is not visible in the diagram. It comes from the tower-floater structural vibration frequency. 
In the case of the semi-submersible platform, the power spectrum in the wave frequency range is relatively small. Instead, there is a higher peak around $2.0 \mathrm{rad} / \mathrm{s}$. This corresponds to the 1 st tower bending mode of $2.10 \mathrm{rad} / \mathrm{s}$ and this peak is categorized as structural vibration. In the case of the TLP platform, one peak is observed in the wave frequency and the other peak in the high frequency range. Similar to the other two platforms, the peak at the high frequency corresponds to the vibration frequency, whose amplitudes are much smaller than the other two platforms.

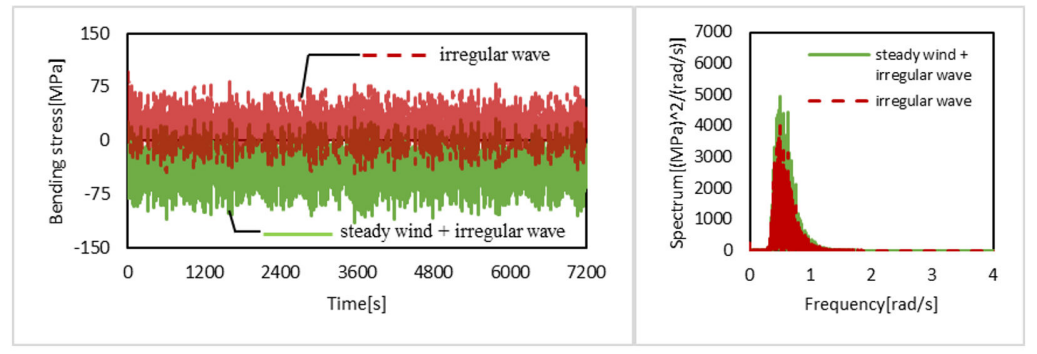

Figure 7. Time history of bending stress and bending stress PSD of spar platform $\left(H_{s}=3.0 \mathrm{~m}\right)$.
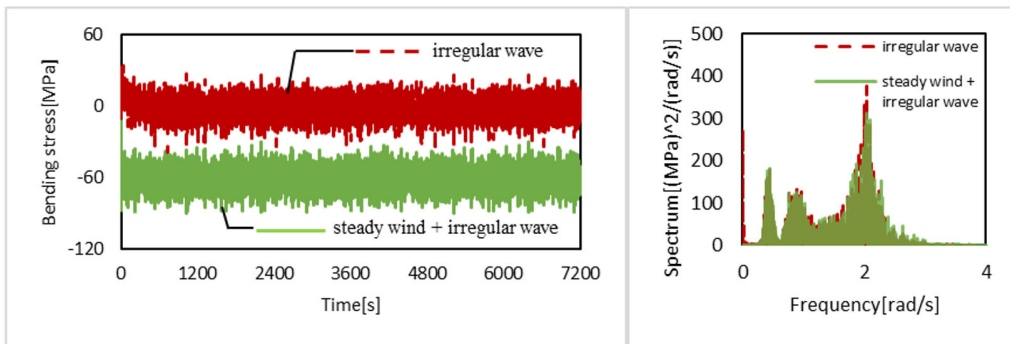

Figure 8. Time history of bending stress and bending stress PSD of semi-submersible platform $\left(H_{s}=3.0 \mathrm{~m}\right)$.
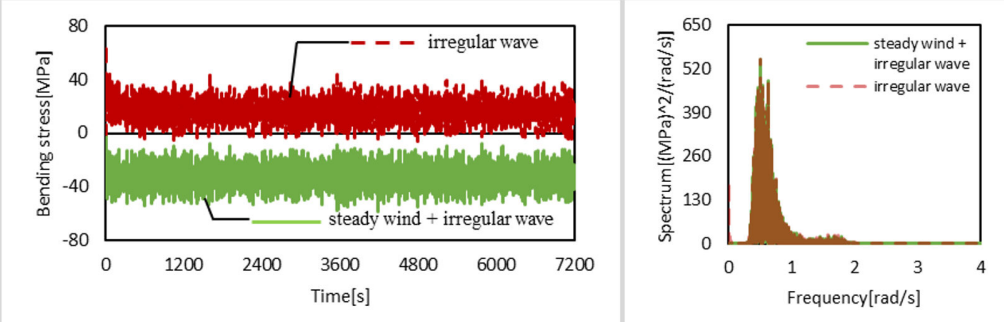

Figure 9. Time history of bending stress and bending stress PSD of TLP platform $\left(H_{S}=3.0 \mathrm{~m}\right)$.

Tables 6-8 show the variance of bending stress at tower base under steady wind and irregular wave condition. Wind speed is kept consistent at $8.0 \mathrm{~m} / \mathrm{s}$, then the variance under the wind-only case becomes zero. For the Spar platform, the variance of the combined case increases due to the coupling effect by $20-30 \%$ compared to the wave-only case. The spectrum in the wave frequency range amplifies due to the coupling of the aerodynamic load between wind and waves as discussed in Equation (8). On the contrary, for the semi-submersible platform, the variance reduces due to the coupling effect by around $10 \%$. From the PSD, one can find out that there is almost no difference in the wave frequency range between wave-only case and combined case, however, the vibration component reduces significantly. It means that the aerodynamic load acts as the additional damping and reduces the vibration amplitude at the natural frequency. These two platforms show the opposite effects, different from each other. Meanwhile, in the TLP case, the PSD under wave-only case and combined case are in agreement. It means that the combined response of the TLP can be given by a simple sum of the wind-only and wave-only response. 
Table 6. Variance of bending stress under steady wind and irregular wave of spar.

\begin{tabular}{ccc}
\hline & $\sigma_{\text {wave }}^{2}\left(\mathrm{MPa}^{2}\right)$ & $\sigma_{\text {com }}^{2}\left(\mathbf{M P a}^{2}\right)$ \\
\hline$H_{S}=1.5 \mathrm{~m}$ & 116.61 & 151.64 \\
$H_{S}=3.0 \mathrm{~m}$ & 448.80 & 583.21 \\
$H_{S}=6.0 \mathrm{~m}$ & 1787.83 & 2223.22 \\
\hline
\end{tabular}

Table 7. Variance of bending stress under steady wind and irregular wave of semi-submersible.

\begin{tabular}{ccc}
\hline & $\sigma_{\text {wave }}^{2}\left(\mathbf{M P a}^{2}\right)$ & $\sigma_{\text {com }}^{2}\left(\mathbf{M P a}^{2}\right)$ \\
\hline$H_{s}=1.5 \mathrm{~m}$ & 19.73 & 17.60 \\
$H_{s}=3.0 \mathrm{~m}$ & 71.32 & 64.18 \\
$H_{s}=6.0 \mathrm{~m}$ & 292.40 & 257.04 \\
\hline
\end{tabular}

Table 8. Variance of bending stress under steady wind and irregular wave of TLP.

\begin{tabular}{ccc}
\hline & $\sigma_{\text {wave }}^{2}\left(\mathbf{M P a}^{2}\right)$ & $\sigma_{\text {com }}^{2}\left(\mathbf{M P a}^{2}\right)$ \\
\hline$H_{s}=1.5 \mathrm{~m}$ & 17.76 & 16.23 \\
$H_{S}=3.0 \mathrm{~m}$ & 62.31 & 61.66 \\
$H_{S}=6.0 \mathrm{~m}$ & 229.66 & 233.51 \\
\hline
\end{tabular}

\subsection{Stochastic Wind and Irregular Wave Condition}

Table 9 shows the variance under stochastic wind-only condition while Tables 10-12 show the variance under stochastic wind and irregular wave conditions. Figures 10-12 show the PSDs of each platform. Among the three platforms, a large peak can be commonly found in low frequency range around $0-0.2 \mathrm{rad} / \mathrm{s}$, which corresponds to the steady component and natural frequency of mooring(spring)-platform(mass) mode. When focusing on the spar platform, the difference takes the positive value for the respective cases, which means the fluctuation of stress cycles amplifies due to the coupling effect even in the stochastic wind condition. Figure 10 compares its power spectral density for Case 3,12, 15. One can confirm that the spectrum amplifies in the wave frequency range due to the coupling effect.

In the case of the semi-submersible platform, the coupling effects are close to zero or tend to decrease the response compared to the simple sum. Similar to the steady wind cases, the structural vibration is found to be reduced under the combined load in the stochastic wind cases. Figure 11 compares the power spectral density of Case $3,12,15$. Around $\omega=2.0 \mathrm{rad} / \mathrm{s}$, there is a peak of the bending stress in the PSD. Under the combined condition, the stress cycles in the resonance vibration range are thought to be reduced by the aerodynamic damping.

In the case of the TLP platform (see Figure 12), the response and the coupling effect are found to be very small. In the wave frequency range, the PSD under combined case increases only a little or takes almost the same as the wave-only case. Even at faster wind velocity (Case 13-15), the increase/decrease due to the coupling effect is within $2 \%$ of the simple sum. It indicates that the coupling effect is very minor in the case of the TLP platform. It also indicates that the rigid body motions of the TLP platform to the waves is small. The small motion and the resulting small coupling effect are owing to the taut mooring system, compared with the other two platforms. The motions in the vertical plane, particularly the motions, are suppressed by the tension leg mooring.

It is commonly observed in the results of the semi-submersible platform under different environmental conditions as in PSDs in Figure 13 that the response spectrum around the wave frequency range $\omega=0.2-1.5 \mathrm{rad} / \mathrm{s}$ is not excited to a large extent. This is because the distance between columns $(=75 \mathrm{~m})$ is close to the half of the wave length at the wave period of $10 \mathrm{~s}(\approx 78 \mathrm{~m})$ and the wave loads are nearly cancelled at this wave period. When the wave period is changed from $10 \mathrm{~s}$ to $6.45 \mathrm{~s}$, the spectrum grows at the wave frequency (around $\omega=1.0 \mathrm{rad} / \mathrm{s}$ ) and the vibration frequency range around $\omega=2.1 \mathrm{rad} / \mathrm{s}$. The vibration seems to have been more excited by the second order term of the 
wave load. Table 13 shows the case of wave period of $6.45 \mathrm{~s}$. The coupling effect is larger at this wave period, too. As for the coupling effect, it is more prominent for the higher wave height cases, which is a common tendency among the results in Tables 10-12.

Table 9. The variance of bending stress under wind-only condition (Case 4, 8, 12).

\begin{tabular}{cccc}
\hline & $\bar{w}=3.0 \mathrm{~m} / \mathrm{s}$ & $\bar{w}=5.0 \mathrm{~m} / \mathrm{s}$ & $-\bar{w}=8.0 \mathrm{~m} / \mathrm{s}$ \\
\hline Spar & $45.03\left(\mathrm{MPa}^{2}\right)$ & $108.65\left(\mathrm{MPa}^{2}\right)$ & $301.33\left(\mathrm{MPa}^{2}\right)$ \\
Semisub & $30.32\left(\mathrm{MPa}^{2}\right)$ & $90.55\left(\mathrm{MPa}^{2}\right)$ & $291.49\left(\mathrm{MPa}^{2}\right)$ \\
TLP & $16.88\left(\mathrm{MPa}^{2}\right)$ & $38.28\left(\mathrm{MPa}^{2}\right)$ & $178.89\left(\mathrm{MPa}^{2}\right)$ \\
\hline
\end{tabular}

Table 10. The coupling effect under stochastic wind and irregular wave condition (Case 5, 6, 7). Mean wind speed is $3.0 \mathrm{~m} / \mathrm{s}$.

\begin{tabular}{cccccc}
\hline & & $\begin{array}{c}\sigma_{\text {wave }}^{2} \\
\left(\mathbf{M P a}^{2}\right)\end{array}$ & $\begin{array}{c}\sigma_{\text {wave }}^{2}+\sigma_{\text {wind }}^{2} \\
\left(\mathbf{M P a}^{2}\right)\end{array}$ & $\begin{array}{c}\sigma_{\text {com }}^{2} \\
\left(\mathbf{M P a}^{2}\right)\end{array}$ & $\begin{array}{c}\sigma_{\text {com }}^{2}-\left(\sigma_{\text {wave }}^{2}+\sigma_{\text {wind }}^{2}\right) \\
\left(\mathbf{M P a}^{2}\right)\end{array}$ \\
\hline \multirow{3}{*}{$H_{s}=1.5 \mathrm{~m}$} & Spar & 116.61 & 161.63 & 172.50 & 10.87 \\
& Semisub & 19.73 & 50.05 & 48.31 & -1.74 \\
& TLP & 17.76 & 34.64 & 32.14 & -2.50 \\
\hline \multirow{3}{*}{$H_{S}=3.0 \mathrm{~m}$} & Spar & 448.80 & 493.83 & 537.92 & 44.09 \\
& Semisub & 71.32 & 101.64 & 101.32 & -0.33 \\
& TLP & 62.31 & 79.19 & 76.15 & -3.03 \\
\hline \multirow{2}{*}{$H_{S}=6.0 \mathrm{~m}$} & Spar & 1787.83 & 1832.85 & 1933.45 & 100.60 \\
& Semisub & 292.40 & 322.72 & 332.44 & 9.72 \\
& TLP & 229.66 & 246.54 & 240.35 & -6.18 \\
\hline
\end{tabular}

Table 11. The coupling effect under stochastic wind and irregular wave condition (Case 9, 10, 11). Mean wind speed is $5.0 \mathrm{~m} / \mathrm{s}$.

\begin{tabular}{cccccc}
\hline & & $\begin{array}{c}\sigma_{\text {wave }}^{2} \\
\left(\mathbf{M P a}^{2}\right)\end{array}$ & $\begin{array}{c}\sigma_{\text {wave }}^{2}+\sigma_{\text {wind }}^{2} \\
\left(\mathbf{M P a}^{2}\right)\end{array}$ & $\begin{array}{c}\sigma_{\text {com }}^{2} \\
\left(\mathbf{M P a}^{2}\right)\end{array}$ & $\begin{array}{c}\sigma_{\text {com }}^{2}-\left(\sigma_{\text {wave }}^{2}+\sigma_{\text {wind }}^{2}\right) \\
\left.\mathbf{( M P a}^{2}\right)\end{array}$ \\
\hline \multirow{3}{*}{$H_{S}=1.5 \mathrm{~m}$} & Spar & 116.61 & 225.26 & 247.91 & 22.65 \\
& Semisub & 19.73 & 110.27 & 107.91 & -2.36 \\
& TLP & 17.76 & 56.04 & 54.19 & -1.85 \\
\hline \multirow{3}{*}{$H_{S}=3.0 \mathrm{~m}$} & Spar & 448.80 & 557.46 & 646.68 & 89.22 \\
& Semisub & 71.32 & 161.87 & 157.71 & -4.15 \\
& TLP & 62.31 & 100.59 & 97.69 & -2.90 \\
\hline \multirow{3}{*}{$H_{S}=6.0 \mathrm{~m}$} & Spar & 1787.83 & 1896.48 & 2164.14 & 267.66 \\
& Semisub & 292.40 & 382.94 & 379.18 & -3.77 \\
& TLP & 229.66 & 267.94 & 264.66 & -3.28 \\
\hline
\end{tabular}

Table 12. The coupling effect under stochastic wind and irregular wave condition (Case 13, 14, 15). Mean wind speed is $8.0 \mathrm{~m} / \mathrm{s}$.

\begin{tabular}{cccccc}
\hline & & $\begin{array}{c}\sigma_{\text {wave }}^{2} \\
\left(\mathbf{M P a}^{2}\right)\end{array}$ & $\begin{array}{c}\sigma_{\text {wave }}^{2}+\sigma_{\text {wind }}^{2} \\
\mathbf{( M P a}^{2} \mathbf{)}\end{array}$ & $\begin{array}{c}\sigma_{\text {com }}^{2} \\
\left(\mathbf{M P a}^{2}\right)\end{array}$ & $\begin{array}{c}\sigma_{\text {com }}^{2}-\left(\sigma_{\text {wave }}^{2}+\sigma_{\text {wind }}^{2}\right) \\
\left.\mathbf{( M P a}^{2}\right)\end{array}$ \\
\hline \multirow{3}{*}{$H_{S}=1.5 \mathrm{~m}$} & Spar & 116.61 & 417.94 & 451.23 & 33.29 \\
& Semisub & 19.73 & 311.21 & 306.58 & -4.63 \\
& TLP & 17.76 & 196.64 & 194.86 & -1.78 \\
\hline \multirow{3}{*}{$H_{S}=3.0 \mathrm{~m}$} & Spar & 448.80 & 750.14 & 889.82 & 139.69 \\
& Semisub & 71.32 & 362.81 & 349.21 & -13.59 \\
& TLP & 62.31 & 241.19 & 240.92 & -0.27 \\
\hline \multirow{3}{*}{$H_{S}=6.0 \mathrm{~m}$} & Spar & 1787.83 & 2089.16 & 2542.85 & 453.69 \\
& Semisub & 292.40 & 583.88 & 527.32 & -56.56 \\
& TLP & 229.66 & 408.54 & 414.39 & 5.85 \\
\hline
\end{tabular}


Table 13. The coupling effect under stochastic wind and irregular wave condition for semi-submersible platform (Case 16, 17, 18).

\begin{tabular}{ccccc}
\hline & $\begin{array}{c}\sigma_{\text {wave }}^{2} \\
\left(\mathbf{M P a}^{2}\right)\end{array}$ & $\begin{array}{c}\sigma_{\text {wave }}^{2}+\sigma_{\text {wind }}^{2} \\
\left(\mathbf{M P a}^{2}\right)\end{array}$ & $\begin{array}{c}\sigma_{\text {com }}^{2} \\
\left(\mathbf{M P a}^{2}\right)\end{array}$ & $\begin{array}{c}\sigma_{\text {com }}^{2}-\left(\sigma_{\text {wave }}^{2}+\sigma_{\text {wind }}^{2}\right) \\
\left(\mathbf{M P a}^{2}\right)\end{array}$ \\
\hline$H_{S}=1.5 \mathrm{~m}$ & 116.61 & 417.94 & 451.23 & 33.29 \\
$H_{S}=3.0 \mathrm{~m}$ & 448.80 & 750.14 & 889.82 & 139.69 \\
$H_{S}=6.0 \mathrm{~m}$ & 1787.83 & 2089.16 & 2542.85 & 453.69 \\
\hline
\end{tabular}

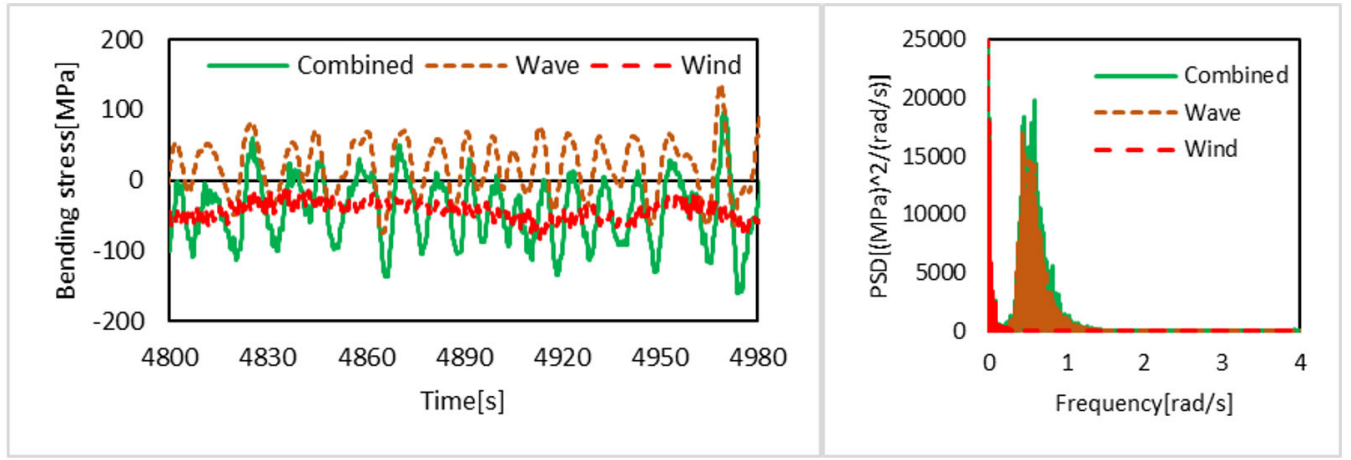

Figure 10. Time history and PSD of bending stress of spar platform (Case 3, 12, 15).

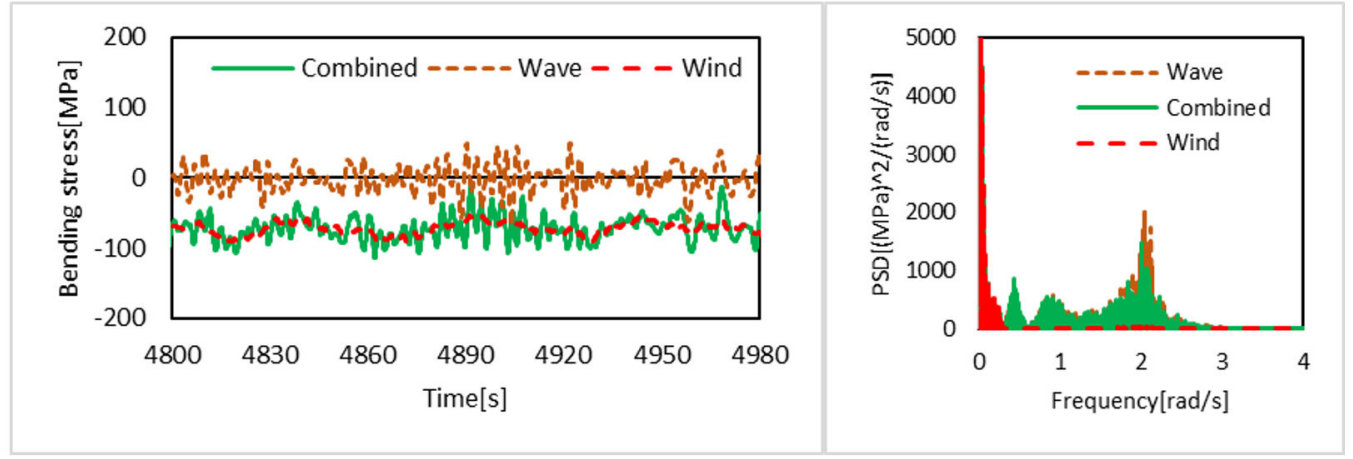

Figure 11. Time history and PSD of bending stress of semi-submersible platform (Case 3, 12, 15).

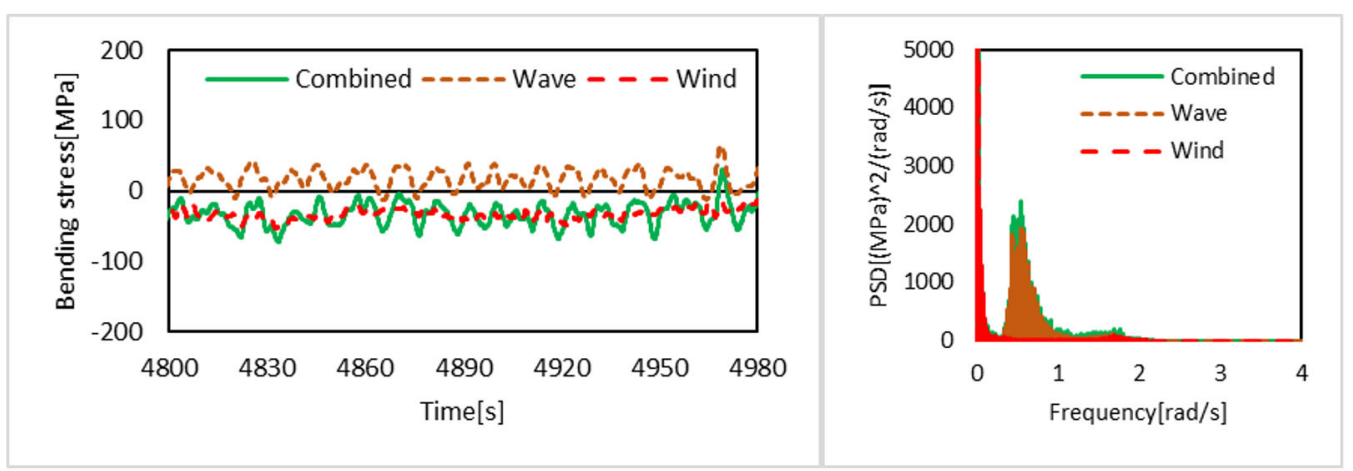

Figure 12. Time history and PSD of bending stress of TLP platform (Case 3, 12, 15). 


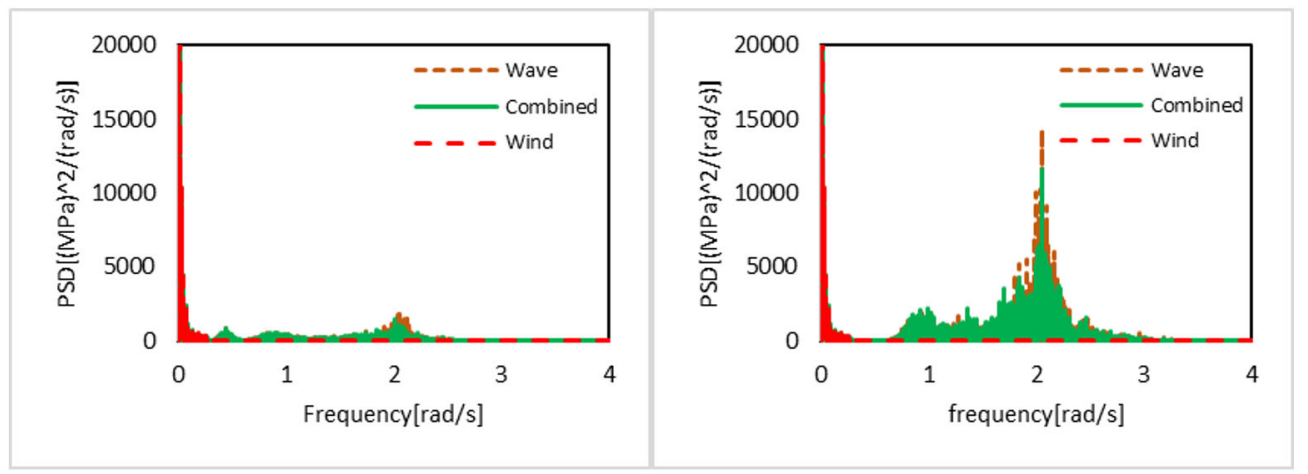

Figure 13. PSD of bending stress with different wave periods (left: Case 15, right: Case 18).

\subsection{Effect of Simulation Length}

In this section, we investigate the effect of simulation length on the variance of the bending stress. The statistical uncertainty should be removed as much as possible. If the simulation time length is sufficient, the error due to the scatter becomes negligible. However, it requires immense computational cost. In this section, conducting the simulations three times each under combined condition using the spar platform. However, the shape of the wind and wave spectrum should be the same. From the time series data, several variations of time length (every $1200 \mathrm{~s}$ to $7200 \mathrm{~s}$ ) was taken out and the variance was calculated for each data. Figure 14 shows the result of the case under $\bar{w}=5.0 \mathrm{~m} / \mathrm{s}$ and $\bar{w}=8.0 \mathrm{~m} / \mathrm{s}$. In both figures, the results show in order from the bottom up $1.5 \mathrm{~m}, 3.0 \mathrm{~m}$ and $6.0 \mathrm{~m}$ of significant wave height. For any case, the error of variance for $7200 \mathrm{~s}$ is within $10 \%$. In the case of $\bar{w}=5.0 \mathrm{~m} / \mathrm{s}$, if we take the simulation length for more than $3600 \mathrm{~s}$, the error is almost within $5 \%$. On the other hand, in the case of $\bar{w}=8.0 \mathrm{~m} / \mathrm{s}$, if we take the simulation length for $4800 \mathrm{~s}$ the error is still more than $5 \%$. However, in both cases, the error tends to converge if the time length is taken for longer than $3600 \mathrm{~s}$. It is noted that if $10 \%$ error is applied to the equation for evaluating the fatigue damage, it can produce the error of the fatigue damage in about $20 \%$ because it is proportional to $\left(\sigma^{2}\right)^{2}$.
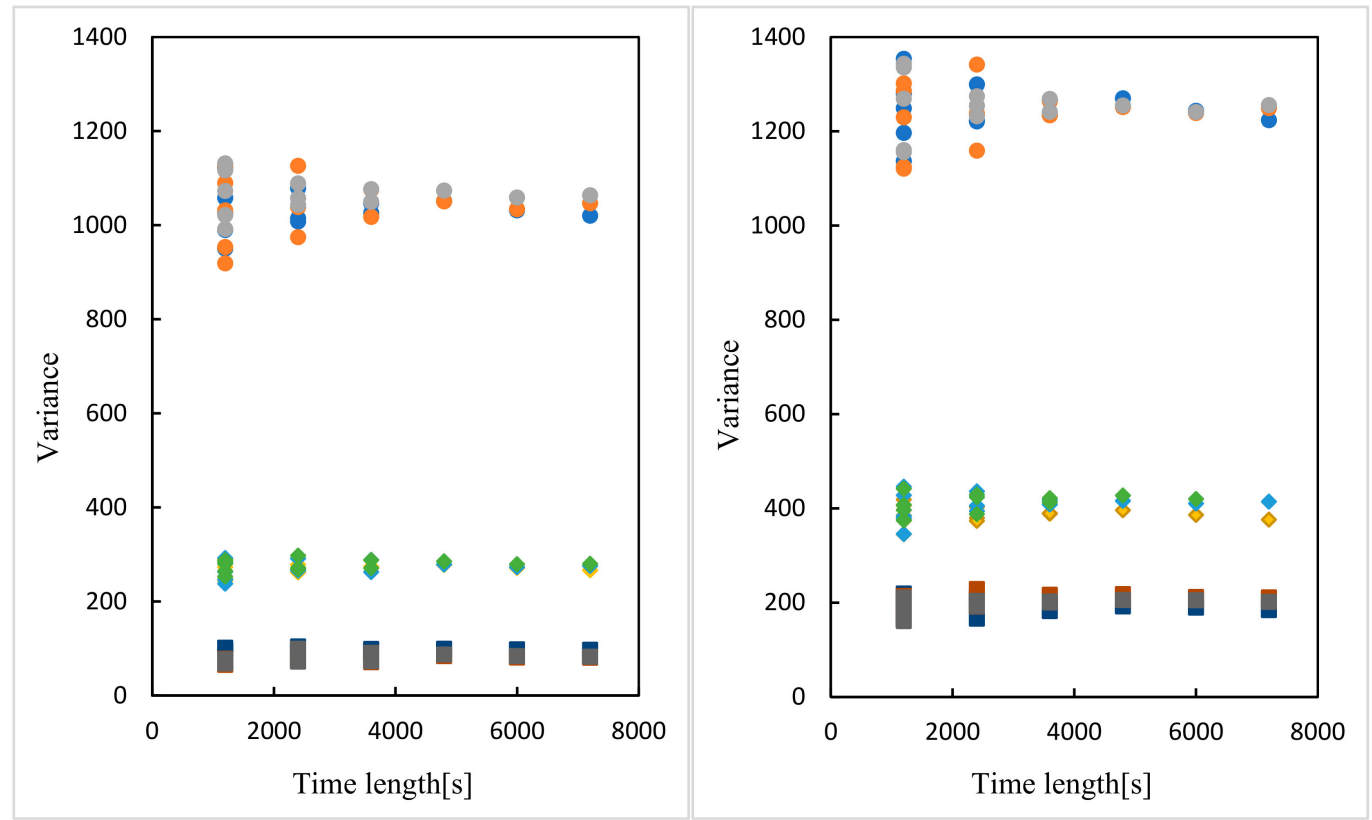

Figure 14. Time length for calculation and the variance in spar platform (left: Case 9, 10, 11, right: Case 13, 14, 15). 


\subsection{Application to Fatigue Damage Evaluation}

In the structural design of FOWTs, fatigue damage during the design life time needs to be assessed. One big contribution to the fatigue damage may come from the very severe conditions that are rarely encountered by the structure. It is not within the scope of the present paper and the fatigue damage under the severe or accidental conditions may directly be calculated by the time-domain simulations under the considered conditions, also by taking account of the pitch control strategies. The other big contribution comes from rather benign conditions that are encountered frequently by the structure. These two may separately be evaluated and summed up.

As regards the latter, Tables 10-12 reveal that the change of the variance depends on the characteristics of the nonlinear coupling effects as discussed in Section 2.2. Figure 15 compares the nonlinear coupling effects in terms of the variance at the vibration frequency in the cases of the semisubmersible platform, as a function the wave height $H$ and the wind speed $w$, respectively. It is clearly observed that the variance of the stress at the vibration frequency decreases with $(w H)^{2}$. Once the variance increase/decrease due to the nonlinear coupling effect is given as an explicit function based on several simulations, one is able to find the variance of the stress in arbitrary combined cases based on two independent simulations, that is, wave-only and wind-only, without performing the simulation under the combined wind and waves. Fatigue damage may be evaluated in a relatively short time, by using the spectral approach over the evaluated variance. Then, the number of bins of wind and waves for the fatigue evaluation can be reduced significantly. It is expected that this should improve the calculation efficiency of the fatigue damage evaluation at the design stage.
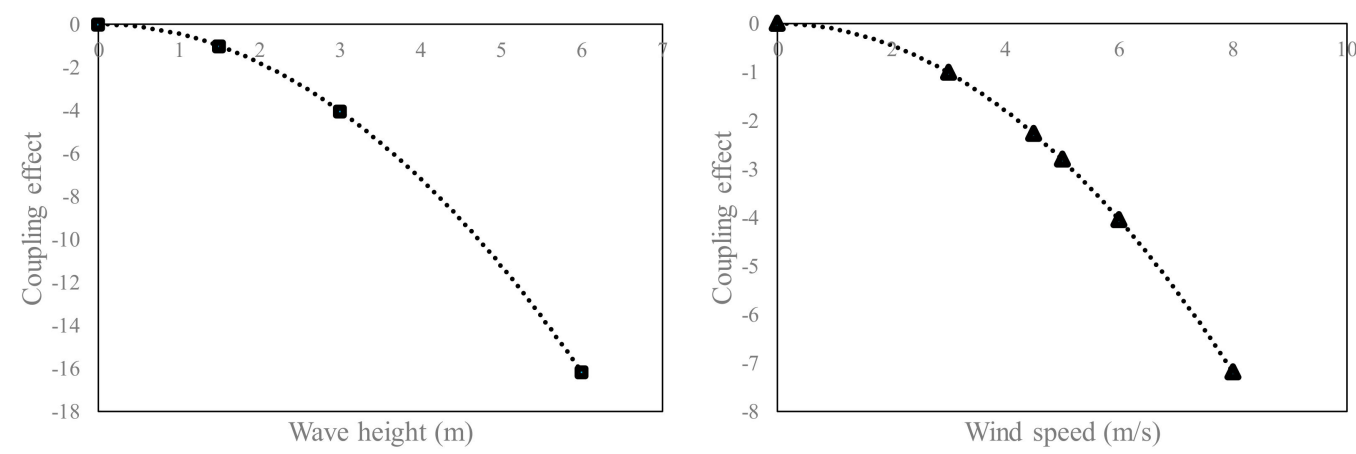

Figure 15. Nonlinear coupling effects in the high frequency component as a function of wave height and wind speed.

\section{Conclusions}

The response characteristics of three FOWTs, that is, spar, semisubmersible and TLP, under the combined wind and wave loads, are investigated with a focus on the nonlinear coupling effects. When wind and waves act on FOWTs simultaneously, the time series of the response is different from a simple sum of those of the independent cases due to the coupling effect. The coupling effects come mainly from the aerodynamic loads. It has been found that the coupling effects can be classified into the vibration reduction by the aerodynamic damping effects and the structural load increase in the wave frequency associated with the rigid body motion induced by the waves. The increase/decrease ratio due to the coupling effects is found to be larger for the larger wave height and faster wind speed cases. The main findings are summarized as follows.

- In the case of the spar type platform in this study, the rigid body motion forced by the waves is relatively large. The relative motion increases the aerodynamic load amplitude in the wave frequency range. The structural load increase is thus observed.

- In the case of the TLP platform in this study, since the structure is tautly moored by the tendons, only little motion occurs. As a result, there is almost no coupling effect. 
- In the case of the semi-submersible platform in this study, the tower vibration component related to the first bending mode is prominent. The motion in the waves is in general small, then the aerodynamic load increase associated with the relative motion is hardly seen. As a total, a reduction of the structural load is observed.

In order to clarify the statistical uncertainty with the time-domain simulation results, the variance of the results with different time durations are compared.

- Simulations for more than $3600 \mathrm{~s}$ are required to avoid the significant scatters. Even in this case, the scatter in terms of the variance of the stress is around $10 \%$ of its mean value. If the simulation results are adopted for the fatigue damage estimation, it could result in an estimation error of about $20 \%$.

In the development of the mathematical models, it is assumed that the blade pitch angle is fixed. The models apply for cases where the blade pitch is not actively controlled in the wind with the mean speed below the rated speed. From the viewpoint of fatigue damage evaluation, most of the environmental conditions should fall into this region. The discussions made here can be utilized for condensing the bins of wind and waves for the spectral fatigue analysis. For the future work, the validity of the proposed formula should be checked for different environmental conditions, particularly with different wave periods. The formula should be applied to predict the fatigue damage efficiently and checked of its validity.

Author Contributions: T.I. and K.I. developed the idea, analyzed the data and wrote the paper; A.A. performed the numerical simulations; S.O. and H.S. gave the discussions about the contents of the paper. All authors have read and agreed to the published version of the manuscript.

Funding: This research has been financially supported by JSPS KAKENHI Grant number 20H02367.

Acknowledgments: Some part of the initial idea of the present study has been developed by Raito Kabashima as a partial fulfillment of the requirements of a master's degree, Osaka University in his master's thesis. It is also acknowledged.

Conflicts of Interest: There are no conflict of interests.

\section{References}

1. Jonkman, J.; Buhl, M. Fast User's Guide; Technical Report, NREL/TP-500-38230; National Renewable Energy Laboratory: Golden, CO, USA, 2005.

2. Oh, S.; Ishii, K.; Hioki, F.; Suzuki, H. Outline of the dynamic analysis procedure in NK-UTWind ver5.0 for offshore floating wind turbine certification. In Proceedings of the 15th World Wind Energy Conference, Tokyo, Japan, 31 October-2 November 2016.

3. Matsuishi, M.; Endo, T. Fatigue of Metals Subjected to Varying Stress. In Proceedings of the Kyushu Branch of Japan Society of Mechanics Engineering; Japan Society of Mechanics Engineering: Fukuoka, Japan, 1968; pp. 37-40.

4. Li, H.; Hu, Z.; Wang, J.; Meng, X. Short-term fatigue analysis for tower base of a spar-type wind turbine under stochastic wind-wave loads. Int. J. Nav. Archit. Ocean Eng. 2018, 10, 9-20. [CrossRef]

5. Mrsnik, M.; Slavic, J.; Boltezar, M. Frequency-domain methods for a vibration-fatigue-life estimation-Application to real data. Int. J. Fatigue 2013, 47, 8-17. [CrossRef]

6. Abhishek, A. Reduction of Fatigue Computational Time for Offshore Wind Turbine Jacket Foundations. Master's Thesis, Delft University of Technology, Delft, The Netherlands, 2018; pp. 47-64.

7. Kvittem, M.I.; Moan, T. Frequency versus time domain fatigue analysis of a semi-submersible wind turbine tower. In Proceedings of the ASME 2014 33rd International Conference on Ocean, Offshore and Arctic Engineering, San Francisco, CA, USA, 8-13 June 2014. OMAE2014-23385.

8. Van Der Tempel, J. Design of Support Structures for Offshore Wind Turbines. Ph.D. Thesis, Delft University, Delft, The Netherlands, 2006.

9. Huang, W.; Moan, T. Fatigue under combined high and low frequency loads. In Proceedings of the 25th International Conference on Offshore Mechanics and Arctic Engineering, Hamburg, Germany, 4-9 June 2006. OMAE2006-92247. 
10. Winterstein, S.R. Nonlinear vibration models for extremes and fatigue. J. Eng. Mech. 1998, 114, 1772-1790.

11. Gao, Z.; Moan, T. Wave-induced fatigue damage of mooring chain under combined non-gaussian low and wave frequency loads. In Proceedings of 25th International Conference on Offshore Mechanics and Arctic Engineering, Hamburg, Germany, 4-9 June 2006. OMAE2006-92389.

12. Dirlik, T. Application of Computers in Fatigue Analysis. Ph.D. Thesis, University of Warwick, Warwick, UK, 1985.

13. Ragan, P.; Manuel, L. Comparing Estimates of Wind Turbine Fatigue Loads Using Time-Domain and Spectral Methods. Wind. Eng. 2007, 31, 83-99. [CrossRef]

14. Adilah, A.; Iijima, K.; Inoue, T. Spectral approach for fatigue evaluation of floating offshore wind turbine under combined wind and wave loads by considering the coupling effect. In Proceedings of the 30th International Ocean and Polar Engineering Conference, Shanghai, China, 11-16 October 2020. ISOPE-I-20-1177.

15. Moriaty, P.J.; Hansen, A.C. AeroDyn Theory Manual; Technical Report, NREL/TP-500-36881; National Renewable Energy Laboratory: Golden, CO, USA, 2005.

16. Sarpkaya, T.S. Wave Forces on Offshore Structures, Reprint ed.; Cambridge University Press: Cambridge, UK, 2014.

17. Nihei, Y.; Ikoma, T.; Kozen, M.; Sato, F.; Murai, M.; Iijima, K. Designing process and motion characteristics of spar type offshore wind turbines. In Proceedings of the ASME 2013 32nd International Conference on Ocean, Offshore and Arctic Engineering, Nantes, France, 9-14 June 2013. OMAE2013-11262.

18. Motohiko, M.; Iijima, K.; Kuroda, Y.; Nihei, Y.; Murai, M. Conceptual design of a single-point-moored FOWT and tank test for its motion characteristics. In Proceedings of the ASME 2013 32nd International Conference on Ocean, Offshore and Arctic Engineering, Nantes, France, 9-14 June 2013. OMAE2013-11259.

19. Nihei, Y.; Matsuura, M.; Iijima, K.; Ikoma, T. New design proposal for the TLP type offshore wind turbines. In Proceedings of the ASME 2013 32nd International Conference on Ocean, Offshore and Arctic Engineering, Nantes, France, 9-14 June 2013. OMAE2013-11263.

20. Jonkman, J.; Butterfield, S.; Musial, W.; Scott, G. Definition of a 5-MW Reference Wind Turbine for Offshore System Development; Technical Report, NREL/TP-500-38060; National Renewable Energy Laboratory: Golden, CO, USA, 2009.

21. Jonkman, B.L.; Buhl, M.L., Jr. TurbSim User's Guide; Technical Report No. NREL/TP-500-39797; National Renewable Energy Laboratory: Golden, CO, USA, 2006.

22. International Electrotechnical Commission. Wind Turbines-Part 1: Design Requirements; International Electrotechnical Commission: London, UK, 2005; IEC61400-1.

23. Warnsinck, W.H. Report of Committee 1 on Environmental Conditions. In Proceedings of ISSC; Technological University Delft: Delft, The Netherlands, 1964.

Publisher's Note: MDPI stays neutral with regard to jurisdictional claims in published maps and institutional affiliations.

(C) 2020 by the authors. Licensee MDPI, Basel, Switzerland. This article is an open access article distributed under the terms and conditions of the Creative Commons Attribution (CC BY) license (http://creativecommons.org/licenses/by/4.0/). 